\title{
التغيرات والتسهيلات
}

\section{التي حصل عليها اليهود في فلسطين \\ في عهر الاتحاديين 9 . 9 - ؛ 919}

\author{
إعداد \\ الباحث/ هيـثم يـاسر عيسى
}





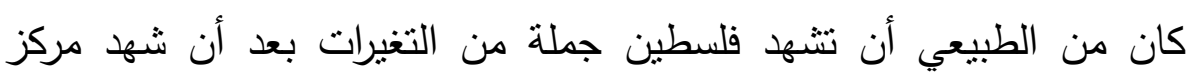

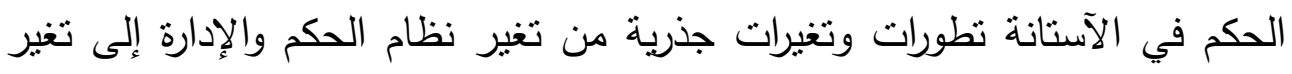

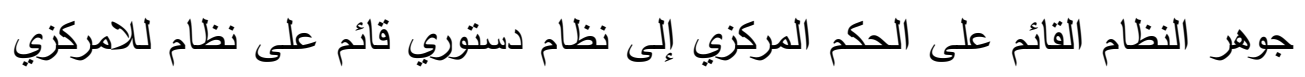

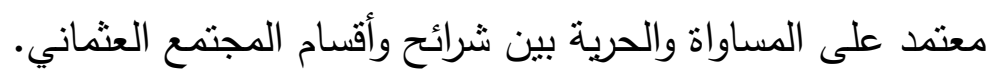

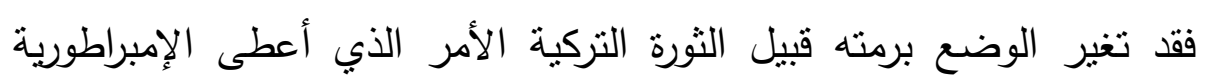

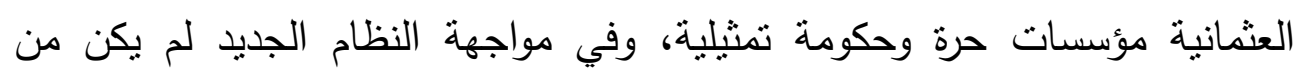

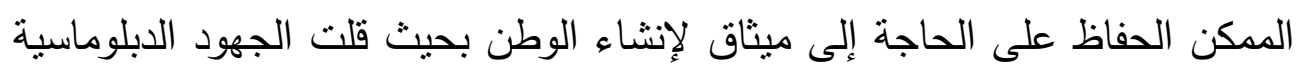

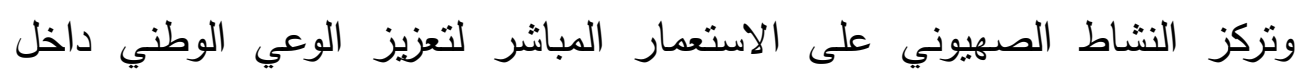

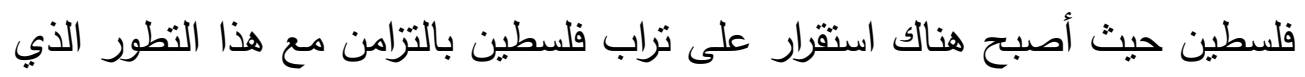

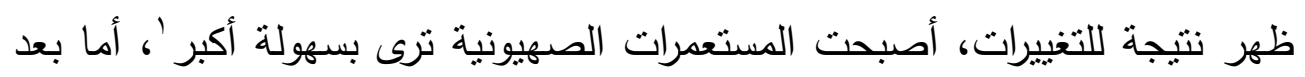

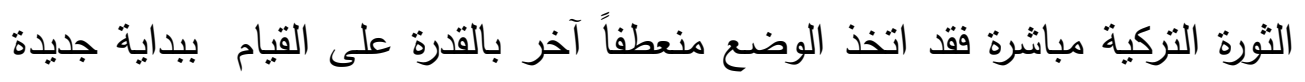

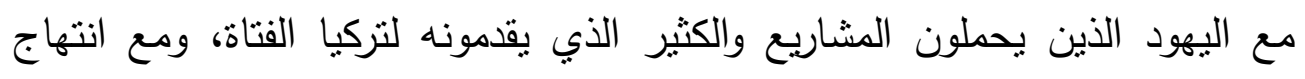

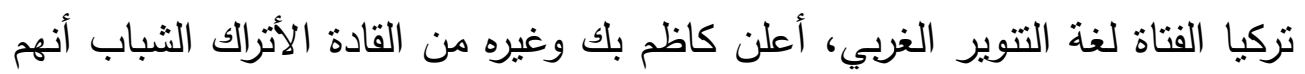

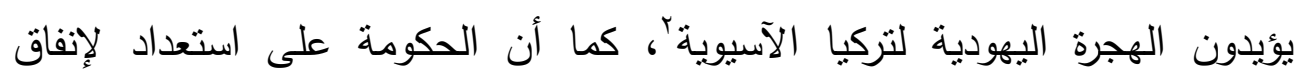

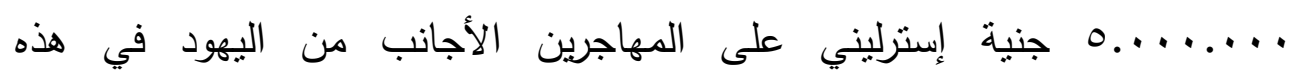

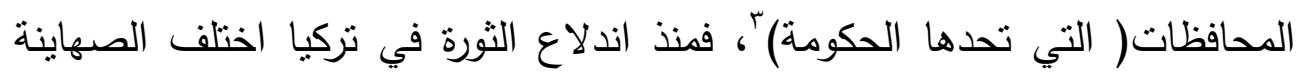

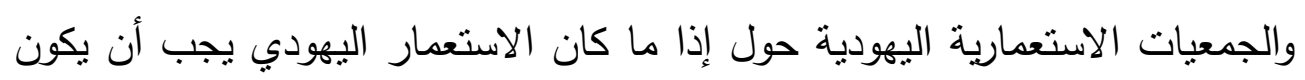

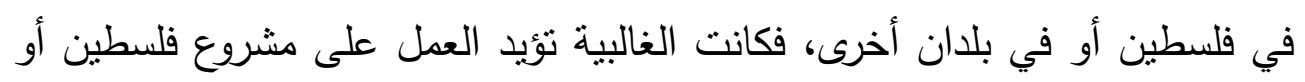

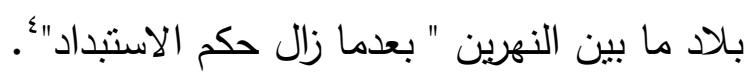

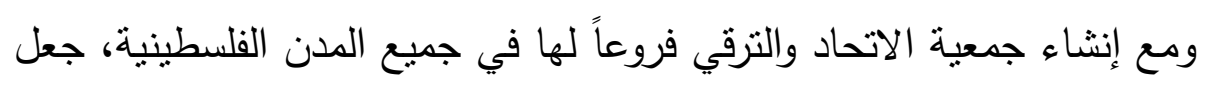

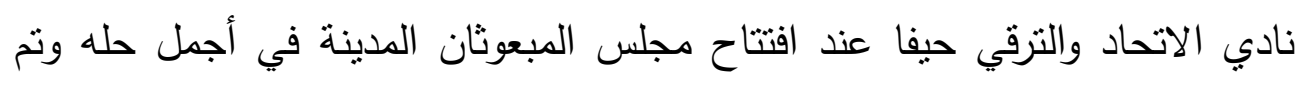

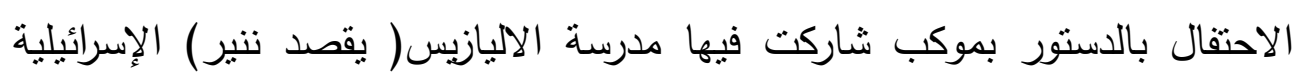

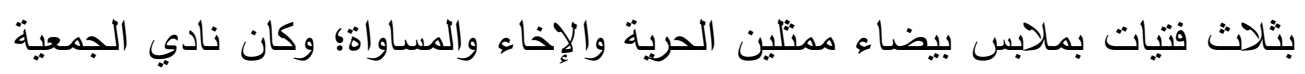

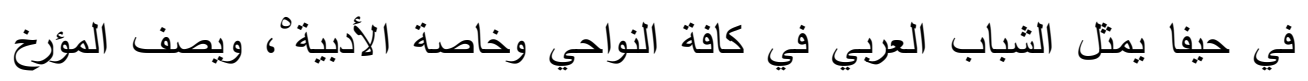


محمد دروزة في مذكراته هذه الفترة بقوله " لقد كان هنالك بوادر يقظة عربية ومطالبة بالحقوق العربية في الدولة بعد ازدياد الوعي لدي عرب فلسطين في نابلس وغيرها، فأنثأوا في نابلس نادياً أدبياً وفرعاً للجمعية الاتحاد والترقي فأخذ الناس ينضمون إليها، فقد أصبحت جمعية الاتحاد والترقي ونواديها في العاصمة والخارج هي المحرك والمحور في الدولة فأخذ الناس يشكون الموظفين لمنع الفساد والرشوة والمحسوبية، خاصة بعد تردد فكرة إنشاء حزب اللامركزية والجمعية العلمية "“، ثم تعزز الوعي العربي ونشطت المقاومة ضد الحركة الصهيونية بعد الانقلاب بقليل، فقد أدرك العرب طبيعة التسهيلات التي منحها النظام الجديد للحركة الصهيونية في فلسطين وبدأت فكرة التعاون بين الاتحاديين والحركة الصهيونية تظهر في الفكر القومي العربي داخل فلسطين ". فاستخل الفلسطينيون فتزة الود القائم بين جمعية الاتحاد والترقي " والعنصر العربي " فصدرث الصحف الوطنية التي اهتمت بحالة المواطن الفلسطيني الفقير مقابل الامتيازات التي يتمتع بها اليهودي الصهيوني؛ فكانت الصحافة الفلسطينية تكتب باستمرار عن الخطر الصهيوني وأثنهر هذه الصحف الكرمل وفلسطين اللتين كثفتا عمليات شراء الأراضي التي زادت في هذه الفترة، وأخذ يصدر منها صحف هُه جديدة قوية الأسلوب ووطنية الهدف تتنقد ما يجب نقده من ظواهر وأعمال وتحذر رئر وتدعو إلى الحد من نفوذ الحركة الصهيونية، وكذللك كانتا جريدتي المفيد والرأي العامج، ثم قام الاتحاديون بانتخابات أعضاء مجلس النواب فحاولت جمعية الاتحاد والترقي أن يكون نواب الثام ممن تثق بهم، أو ممن عرفوا بميلهم إلى الحرية وبعدهم عن السياسة الحميدية ولكنها سعت لتقليل عددهم في الثام"'، حيث ثم انتخاب عن سنجق القد ثلاثة أعضاء وهم سعيد بك الحسيني وروحي بك الخالدي من القس وحافظ بك السعيد من يافا؛ وعن لواء نابلس الشيخ أحمد أفندي الخماش وعن لواء عكا الثيخ أسعد افندي شقير"'، فقد أراد أعضاء جمعية الاتحاد والترقي تمحيص وابل شوائب الأعضاء والموظفين السابقين من البلاد الذين يظلمون الناس بأحكام الرشوة؛'، 
ويصف المؤرخ الفلسطيني محمد عزة دروزة' بالقول " أن الناس في نابلس انفجرت

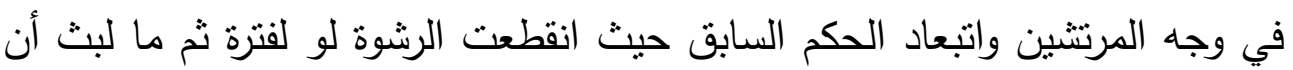
عادت؛'، فقام الاتحاديون في الآستانة بعزل الكثير من الولاة والمتصرفين والقائمقامين

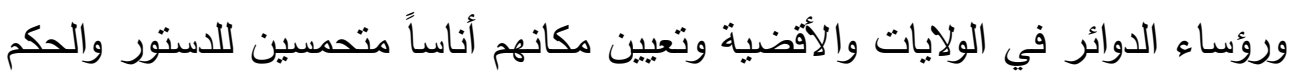

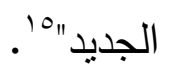

وكانت هذا الإجراء من ضمن مجموعة من الإجراءات التي اتخذها الاتحاديون

في فلسطين فقد استطاعت حكومة الاتحاديين في بداية الأمر زرع الأحلام والأماني للأهل فلسطين وللعرب أجمعين، ولكن مع انكثاف التعاون الصهيوني بينهما، وتهميش العنصر العربي داخل الحكومة ومحاولة فرض سياسة " العثنة " أو " التتريك"1" " على العنصر العربي خوفاً من انفصال العرب عن الدولة العثمانية، استخدمت الحكومة الاتحادية سياسة التعليم الإجباري لتحقيق الانصهار بين العناصر الإسلامية والعناصر غير الإسلامية، ويبدو أن سياسة الحكومة السياسية والاقتصادية

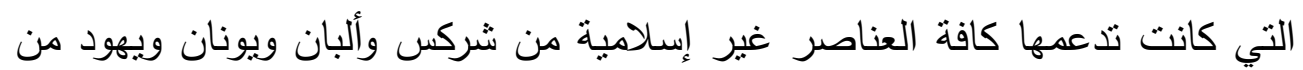
أجل تكوين الدستور يتواقف مع سياسة التتريك، على الرغم من أن الجميع يعلم أن مئن المجتمع العثماني من حيث الدستور هو هيكل قانوني أما اللغة الرسمية فكانت فالأكثرية هي من تتحكم 'ال. ولقد لعب اليهود الأوروبيون واليهود المحليون داخل الدولة العثمانية دوراً مهماً في إرساء تيار القومية الطورانية من خلال إصدار (موئيز كوهين^) ) كتاباً عن أصول الفكرة القومية الطورانية، وإبراهام غالانتي وهما من أعضاء جمعية الاتحاد إناء

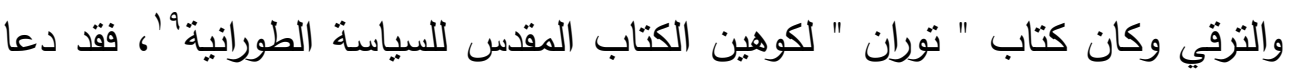
في كتاباته إلى المميزات العسكربة التي سوف تحصل عليها الدولة من انتشار الحركة

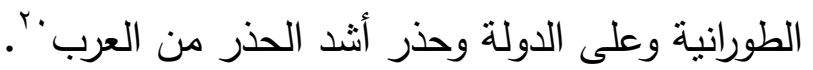
فقد أعرب الاتحاديون عن قناعتهم بأن توحيد الأمة العثمانية عن طريق دمج

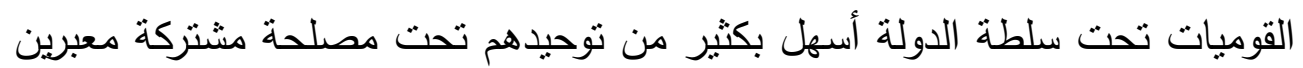


عن قناعتهم بأن " العثمنة" كفيلة بالحفاظ على اتحاد الدولة العثمانية، وأن نطبيقها لن يتسبب بالضرر لأي من العثمانيين واعتمد الاتحاديون في دعوتهم إلى الى التيان

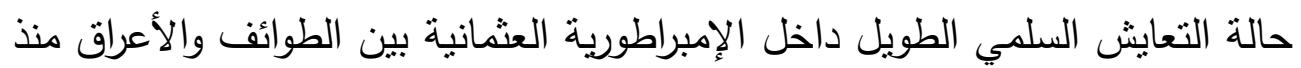

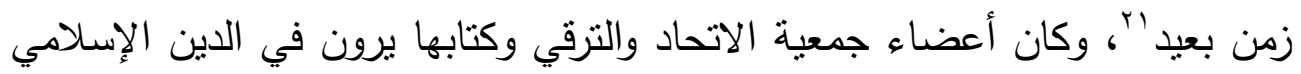

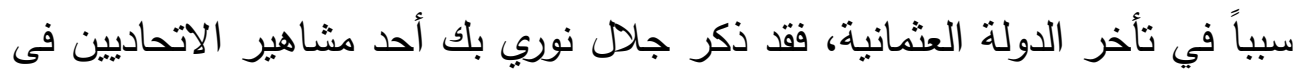

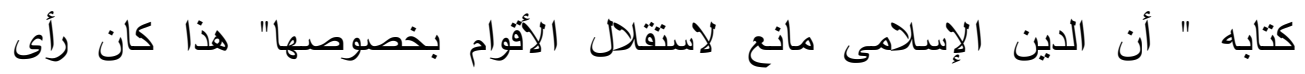

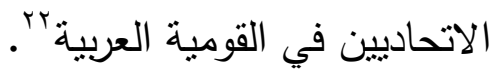

\section{الاتحاديون والهجرة والقروض اليهودية:}

أعطت جمعية الاتحاد والتزقي آمالاً جديدة لليهود نتيجة للعطف الذئه الذي أبداه

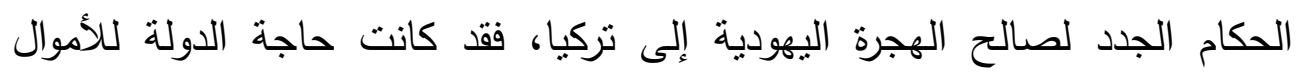

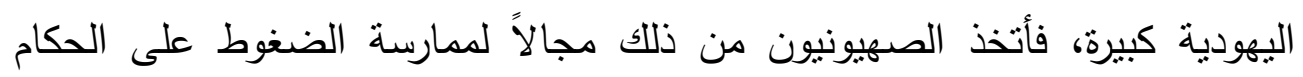

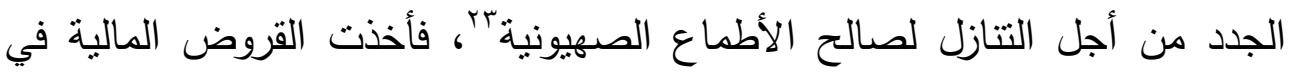
الدولة تنتشر وساد الخلاف في مجلس المبعوثين حول قيمة القروض، حيث يشرح

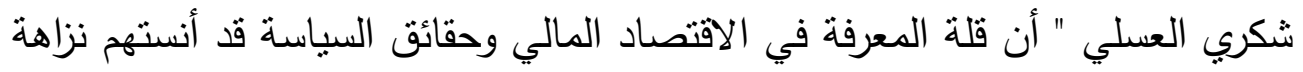

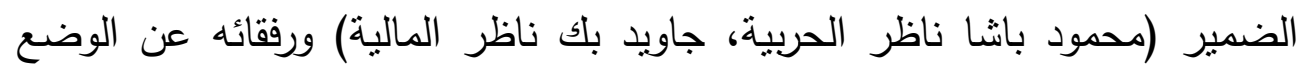

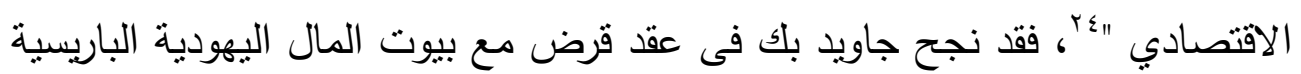

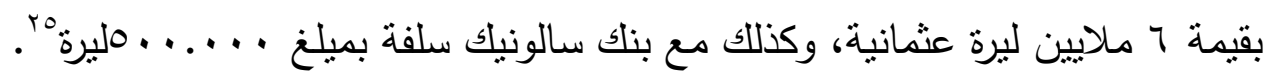

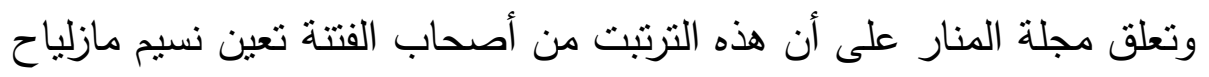

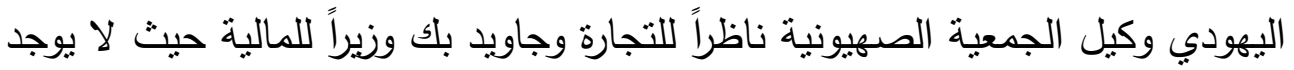

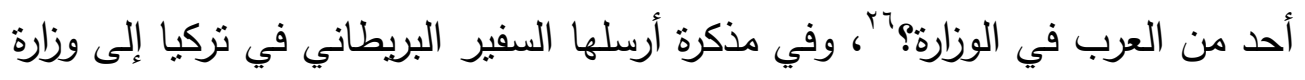

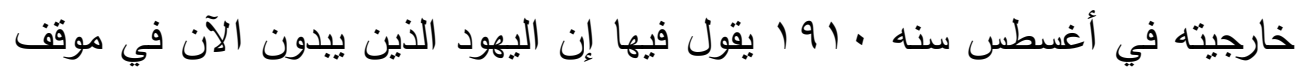
الملهم والمسيطر على الجهاز الداخلي للاولة يعملون على السيطرة الاقتصادية والصناعية على تركيا الفتاة وييدون مصمين... فإنهم يشجعون الاتجاهات القومية التركية"rV ويصف الثيخ رشيد رضا بعد أن عاد من الأستانه نفوذ اليهود في الدولة " 
رأينا أن نفوذ اليهود في جمعية الاتحاد والترقي عظيم... فعلنما أنه سيكون لليهود شأن

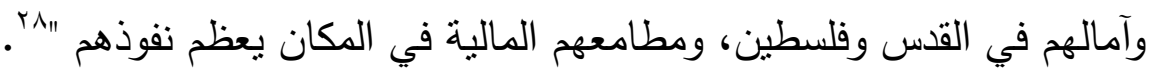
وكانت سياسة الدولة العثمانية الرأسمالية الليبرالية الاقتصادية تعمل على تقوية

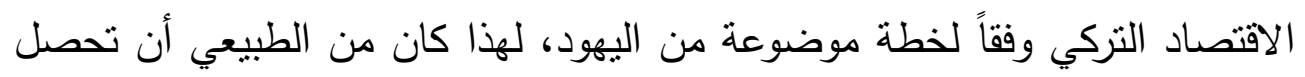
الدولة على القروض من القوى الغربية، وبالتالي حصولها على الامتيازات، وعلى تشجيع رأس المال الأجنبي على الاستثمار، وبالتالي أظهرت نركيا الفتاة خاصة الليبراليين سذاجة دبلوماسيةج"، ويبدو أن اليهود قدموا خدمات هائلة لتركيا الفتاة النيا لمقاضاتهم بالمشروعات الاقتصادية الوطنية لتركيا الفتاة، وخاصة في فلسطين وبلاد

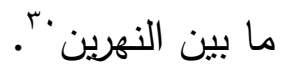
ومن هنا أخذ مجلس المبعوثين في إزالة كل العراقيل الذي تعارض الهجرة الصهيونية إلى فلسطين خاصة عن جمعياتهم الموجودة في استانبول فعلى اليهود أن يغتموا هذه الفرصة" آ، ولم يفكر زعماء اليهود في إثارة الأتراك والعرب ضد مشروع الهجرة، فقد كان موقفه المعلن للأتراك أنه لا يريدون أخذ فلسطين من الدولة العثمانية بل يريدون السكن فيها تحت الرعاية العثمانية بّ، كما لعبت السياسة المالية

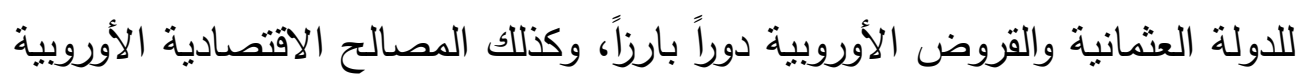
داخل الدولة العثمانية، حيث أصبح موضوع تقسيم الإمبراطورية العثمانية موضوعاً

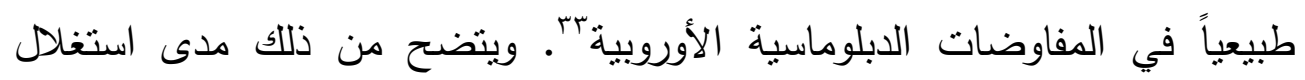
اليهود حاجة الدولة العثمانية إلى الأموال بالتعاون مع القوي الاستعمارية وخاصة بريطانيا، نظرا لأن اليهود يمكنهم تقديم القروض والأموال دون تقبيم الدولة العثمانية بالشكل واسع الذي تعمل على تحقيقه الدول الأوروبية فكان الاتجاه للمال اليهودي أمراً لا مفر منه.

ويصف الكاتب جلال نوري هو كريتي في رحلتة الأخيرة مع الوفد العثماني إلى إنجلترا، بدأ تطوير ما يمكن تسميته الأعراض المعادية للسامية، ومنذ ذلك الحين نشرت مقالاً من عدة ورقات تحذر مواطنين من أخطار استغلال الدولة العثمانية من 
خلا المتمولين اليهود، الذين يستغلون العجز في الموازنة لاستعمار بلاد ما بين

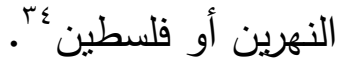

ولكن من جهة أخرى كان عمل اليهود من خلال المناصب التي وصلوا إليها

على تفتيت الدولة العثمانية مستمر هذا ما يؤكده الثيخ رشيد رضا " ... ها هو ناظر المالية يبيع أحسن موقع عسكري في الأستانه لثركة أجنبية بثمن دون الثمن

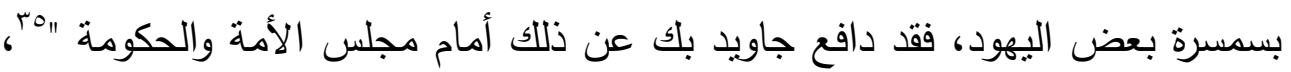
وهذا المكان هو ساحة فسيحة بالقرب من ثكنات تقسيم ( الآن ميدان تقسيم في العاصمة التركية) ثم أخذ موضوع القروض المالية اليهودية يعزز موقف المعارضة فقد انتقد " إسماعيل بك " سياسة الحكومة في عقد القروض أثثاء مناقتنة ميزانية الدولة قائلاً " إن للصهيونيين دخل عظيم في ذلك، أنهم يضعون الصعوبات المالية ليضطروا للاتجاه إليهح "؛ وشدد على أن بيوت المال اليهودية تتعامل مع الصدر الأعظم وطلعت بك، وأن ارنسيت كامل أحد أصحاب هذه البيوت فرد عليه طلعت بك لك " أنه لم يكن لله علاقة بالقرض الأخير ولا بيوت الأموال الصهيونية"“ّ، فرد إسماعيل بك بطلب حساب الأموال التي وجدت في قصر يلديز بعد خلع السلطان عبد الحميد ثم قال " إن الحكومة تتفذ سياسة هؤلاء وتشمح لهم بشراء الأراضي في فلسطين حتي لهي يتم تأليف دولة يهودية هناك"

على الرغم من إتجاه الدولة العثمانية إلى فرنسا وإيطاليا لعقد القروض إلا أن الصهاينة استطاعوا استغلال نفودهم داخل هذه البلاد وقوتهم المالية حتي يكون من خلالهم، وكان الإفلاس الذي يهدد الدولة العثمانية عاملاً من عوامل الضغط على الحكومة العثمانية، فعلى الرغم من رفض الحكومة القرض الفرنسي الكبير، لكن كان تم الضغط على الدولة من خلال إلزامها بتطبيق سياسة الإصلاح داخل المؤسسات

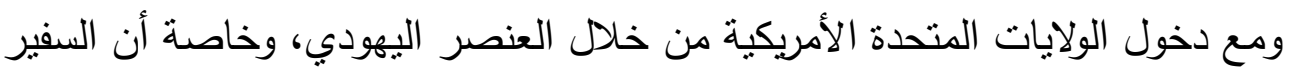

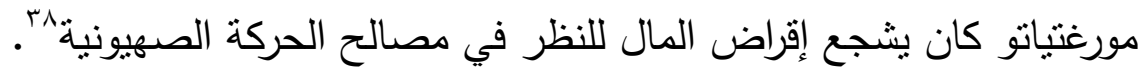


فقد كان اليهود يريدون فلسطين لا غير على الرغم من أنهم اتجهوا للعمل على مشروع استعمار العراق فتم إسكان بعض من إخوانهم في الدين من روسيا ورومانيا

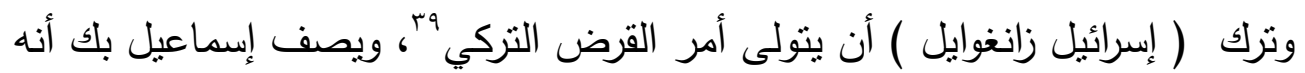
كلما تم رفض طلباتهم كانت نشتخل الدسائس من خلا استخدام المال لعرقلة الحكومة وإثارة الفتن، وها هو السير أرنست كامل بهودي بربطاني ينشئ البنك الأهلي

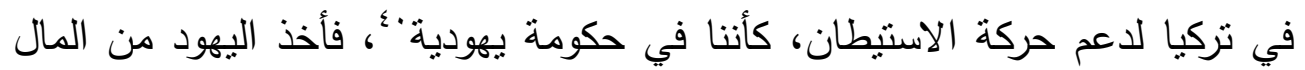
والدعم الاقتصاد العثماني مجالاً واسعاً لضغط على السلطات العثمانية لإجراء تسهيلات لاخول فلسطين، فقد لعبت الجالية اليهودية في استانيول دوراً مهماً في ذلك، من خلال قياداتها خاصة مع وصول الحاخام ناحوم الذي شجع الاستيطان اليهودي في فلسطين. فقد ازدادت حركة الهجرة إلى فلسطين بفضل أهم منظمة للتعامل مع الهجرة اليهودية إلى فلسطين " لجنة أوديسا " فبالنظر إلى أرقام الهجرة الصهيوينة من ميناء

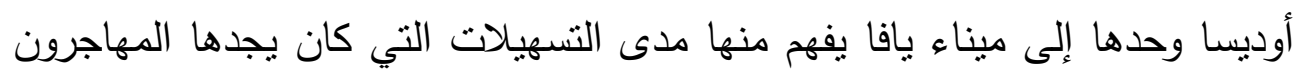
الصهانية إلى فلسطين.

جدول بأعداد المهاجرين من ميناء أوديسا إلى ميناء يافا'؛

\begin{tabular}{|c|c|}
\hline أعداد المهاجرين الواصلين إلى ميناء يافا & 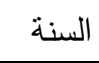 \\
\hline Ir. & 19.0 \\
\hline$r \leq 0$. & 19.7 \\
\hline 180. & $19 \cdot v$ \\
\hline$r .9 V$ & $19 \cdot 1$ \\
\hline$r \leq 09$ & 19.9 \\
\hline rrvq & 191. \\
\hline TrYT & 1911 \\
\hline rAr. & 1914 \\
\hline YqVT & 1914 \\
\hline
\end{tabular}

وتدل هذه الأرقام على زيادة النشاط الصهيوني في فلسطين، فقد ارتفعت أعداد 
المهاجرين منذ عام 19.1 منذ تولى الاتحاديين أمور البلاد، وذلك يرجع إلى التسهيلات التي تلقاها اليهود من حكام الدولة العثمانية، كما تدل هذه الأعداد التي

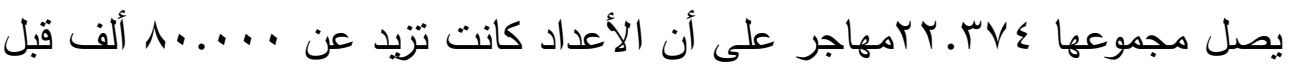
الحرب العالمية الأولي علماً أن هذه الأعداد فقط تصل من ميناء أوديسا فقط. وكان لجنة أوديسا التي أخذت زمام المبادرة في معظم التجارب الاستعمارية

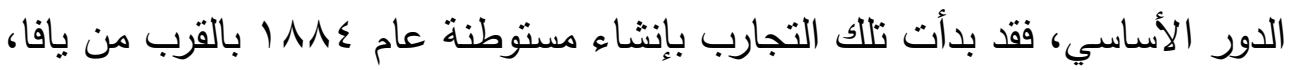
كما استمرت اللجنة تتعاون مع المنظمة الصهيونية، والصندوق القومي الصهيوني وبحلول عام ع191 كانت قد تأسست العديد من المستوطنات الصغيرة بدعم من

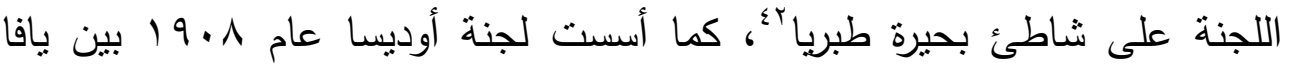
والقدس حوالى • امستعمرة يهودية كلها تقرببا زراعية وأغلبها صغيرة جداً وهي رقيقة الحال "•. ويدل هذا الانتشار السريع للمستعدرات على مدى السهولة التي كان يجدها الصهاينة جراء تغيير نظام الحكم. الإجراءات التي اتخذتها حكومة الاتحاديين في فلسطين: اتخذ الاتحاديون بعد وصولهم إلى كرسي الدولة عدداً من الإجراءات داخل فلسطين كانت سبباً في تسهيل هجرة واستيطان اليهود فيها، فقام الاتحاديون في بداية حكمهم بإعلان قانون الولايات الجديد الذي استفاد منه اليهود لأنه جاء متضامناً مع حركة الاستيطان اليهودي، فقد أصبح في استطاعتهم أن ينتخبوا عدداً من الأعضاء في مجلس العموم داخل متصرفية القد، الأمر الذي مكنهم من التصرف كما يشاؤون، كما سعي منتفذو اليهود في الأستانه لدى الحكومة تعديل حدود متصرفية القدس الإدارية وإلحاق الأراضي المجاورة لهاء؛ وتتقل جريدة القبس عن جريدة طنين الاتحادية التي تصدر من الأستانه أن هدف التعديلات هو زيادة مراقبة نظارة الداخلية

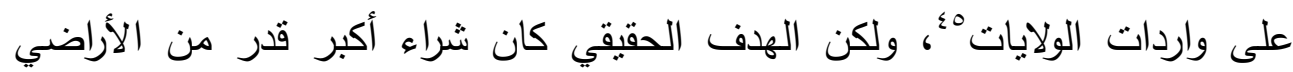
داخل متصرفية القد، التي تعتبر الهذف الرئيسي للحركة الصهيونية، فقد أدركت الحركة الصهيونية ذلك من أجل خلق كثافة سكانية في فلسطين. 


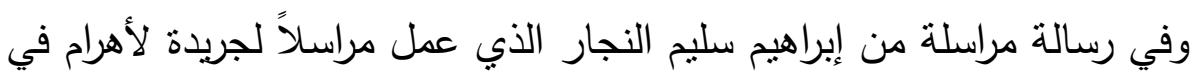

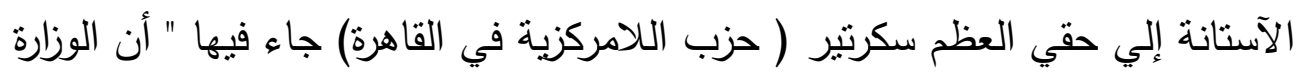

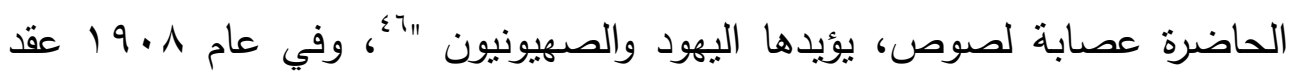

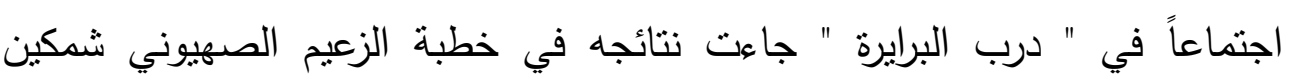

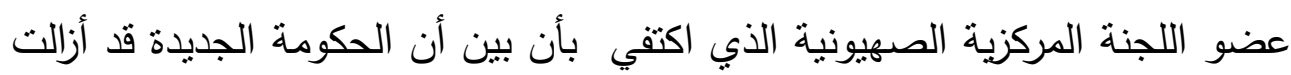

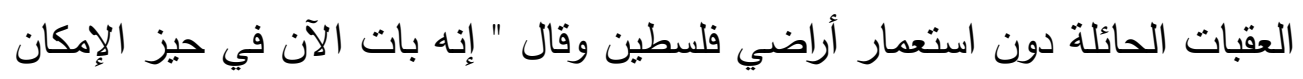

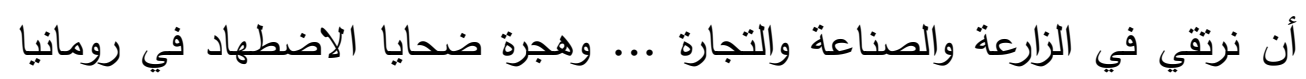

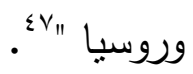

وقد أرسل الحاخام الأكبر ناحوم إلى وزير العدل مذكرتين يطالبه فيها إلغاء

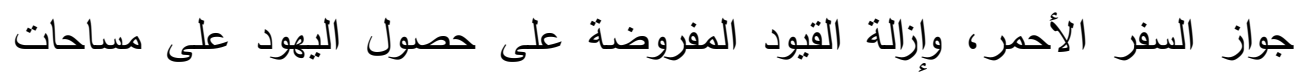

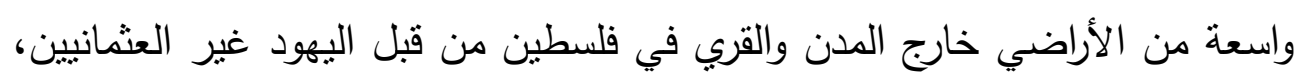

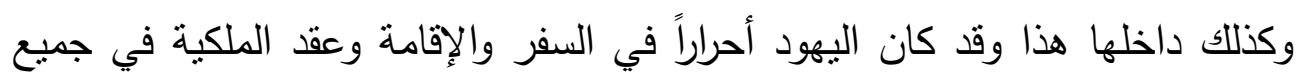

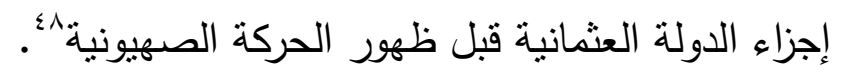
فقامت جريدة الكرمل على أثر ذلك بالهجوم على الحكومة الحهن الاتحادية وعلقت

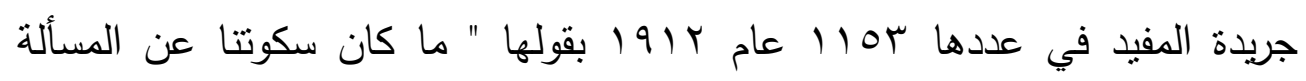

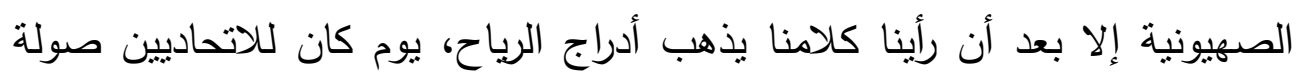

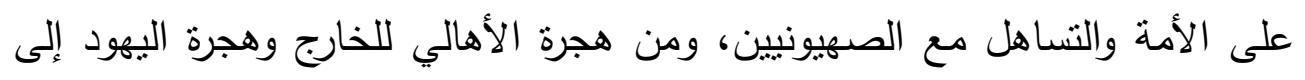

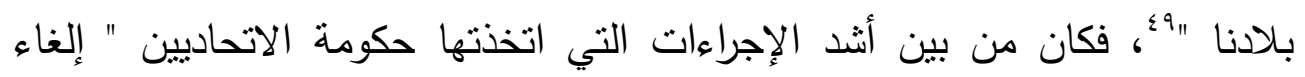

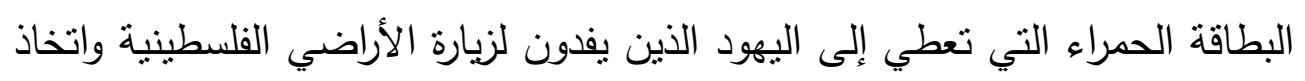

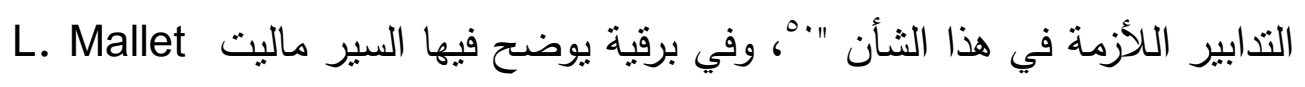

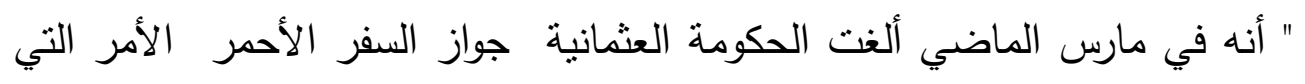

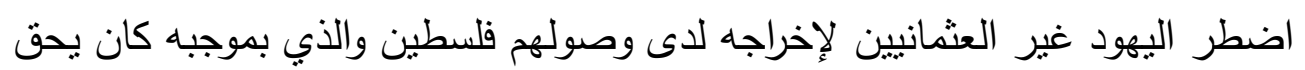
لهم البقاء ثلاثة شهور فقط في فلسطين، حيث أصبحت الهجرة غير مقيدة لليهود إلى لى لإنى 
فلسطين أمر واقع، ومن المتوقع أن تتدفق أعداد كبيرة من اليهود إلى تلك المنطقة ستبدأ قربيا.

وتعقب جريدة الكرمل على كذلك بالقول إن أمر إلغاء الورقة الحمراء والتسريح للمهاجرين الإسرائيليين بالدخول إلى فلسطين والإقامة فيها خطوة كبري في سبيل بلوغ الصهيونيين أمانيهم باسترداد البلاد، وتضيف أما نحن فنعتقد أن الورقة الحمراء لم تكن حائلاً دون دخول المهاجرين الصهيونيين إلى فلسطين وإقامتهم فيها لأن الورقة كانت حبراً على ورق، في وجه التيار الجارف ولا تزال الهجرة في ازدياد إلى يومناً هذا دون مانع، ولا معارض، حيث يستولى الصهيونيون على القرى والمزارع، وكذلك على المشاريع الاقتصادية واذا استمر الحال على ما هو عليه فلا يشاهد سوى قبعات

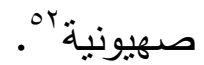
وتصف جريدة الأهرام الأمر أن قلق الأهالي ليس من انتشار اليهود، فقط إنما من الاستور الذي ساوى بين اليهود والمسلمين والنصارى، ولكن الخطر الأكبر هو الهو الهي هجرة اليهود من دول مختلفة بدعوى رابطة الذين لا وطن لهمّ"، ومع سياسة غض الطرف عن سياسة الاسنتطان الصهيوني في فلسطين وعمليات شراء الأراضي الواسعة، وعدم تتفيذ القوانين الموضوعة على الرغم من أن القوانين نفسها هي التي كانت أيام السلطان عبد الحميد، لم تمنع زيادة أعداد المهاجرين اليهود وعمليات شراء الأراضي، لم تحرك الحكومة من الأمر شيئًا بل أخذت تصدر القرارات في صالح الاستيطان اليهودي في فلسطين، على الرغم من معارضة أهالى البلاد.

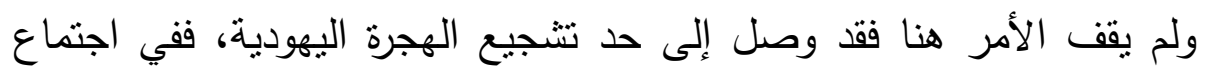
اللجنة التنفيذية للاتحاد الصهيوني في أمريكا عام 9.9 1 جاء فيه أن الأجواء مواتية لغاية للعمل الصهيوني، فمع دعم السفير الأمريكي وزوجه فإن الدولة العثمانية قد سمحت بهجرة . ... . يهودي للاستيطان في فلسطين، كما قامت زوجة السفير الأمريكي بتققد ودعم الجالية اليهودية والمنظمات اليهودية في استانيول، وذلك بتهئة 
الظروف الاقتصادية لهم ؛ُ، وعلى الرغم من ذلك فعلينا الاعتراف بأن الظروف الدولية

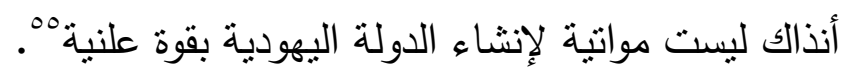

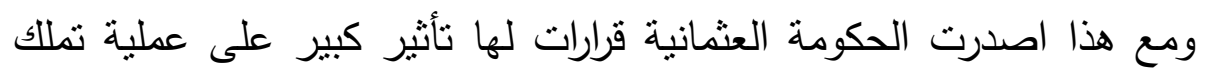
وانتقال الأراضي، فقد كانت أراضي فلسطين ذات ملكية مشتركة (أي نظام المشاع ) بحيث يستحيل على الملاك الحصول على صكوك ملكية خاصة بحصصهم الأمر الار الذي يمنعهم من بيع حصصهم، إلا أن القرار الذي اتخذته الحكومة بتحديد حصص الملاكك المشتركين بناءً على طلبهم وتسليمهم نسخة من صك الملكية، أحدث أثراً كبيراً داخل الحركة الصهيونية واستقبل القرار بارتياح كبير من قبل اليهود ومؤسسات الإستيطان"، وبذلك بدأت عمليات بيع أراضي السلطان " الجفالك " لليهود والصهيونيين وإعطائهم الامتيازات الزراعية والصناعية والتجارية وما فيها من سمسرة

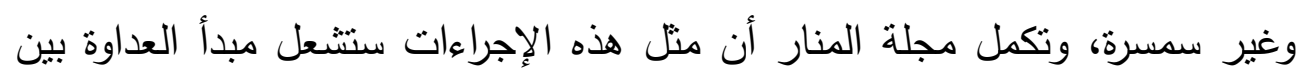
اليهود والعرب الأمر الذي سوف يصل إلى سفلك الدماء لْه وكان للضغوطات البربطانية على حكومة الاتحاد والترقي الأثر الأكبر على فلسطين وتمكين اليهود فيها فأفرزت هذه الضغوط قانون " تصرف الأشخاص الحكمية " الذي أعطي الثركات حق التملك والتصرف بالممتلكات غير المنقولة، وقد تمكنت المؤسسات الصهيونية من استغلال القانون الإنقضاض على أراضي فلسطين هُ وأسفرت الضغوطات عام 1911 منحٌ الأجانب حق التملك والتصرف فى الأراضي كالعثمانيين تماماً في جميع الأراضي العثمانية ما عدا منطقة الحجاز بلا قيد أو شرط سوى ما بتعلق بالثؤون الإجرائية والإداريةهُ، وكان لصدور قانون نزع الملكية

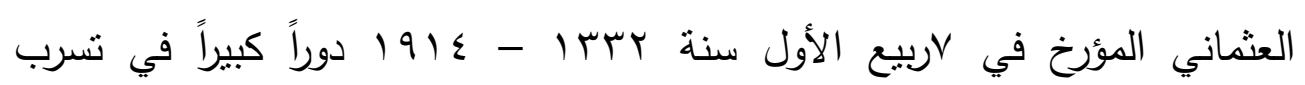
الأراضي لليهود “". وكذلك لعبت ألمانيا دوراً بارزاً في حركة الاستعمار الصهيوني، فقد كانت على علاقة قوية مع جمعية الاتحاد والترقي، حيث استطاعت من خلا هذه العلاقة أخذ العهود والمواثيق على تسهيل السبيل ليهود ألمانيا الصهيونيين في 
( فلسطين)، لأن ألمانيا كانت ترى في العنصر

استيطان الأرض المقدسة

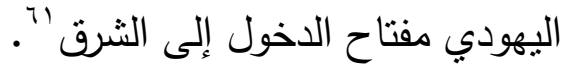

ويصف المؤرخ نجيب نصار الذي جرى في فلسطين عقب تولي الاتحاديين

شؤون البالاد أن بعض ماليي اليهود عرض على الحكومة العثمانية عقد سلفة على شرط أن تمنحه امتيازاً باستثمار بعض الجفالك الأميرية في سوريا وفلسطين، ويضيف أن الصهيونيين يتحينون منل هذه الفرصة ليستولوا على قطعة من أملاك الدولة

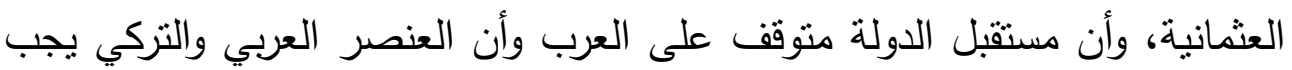
أن يتعاونوا حتى تتهض البلاد لا أن يتم الاعتماد على العنصر الصهيوني بّ، ومصع هذا نجد أن الحركة الصهيونية أتبعت نهجاً تدعي فيها أن سلامتها من سلامة الدولة العثمانية (فلا نجد بلاداً نأمن بها على أروحنا غيرها وأنتا نحرص على المشاركة في

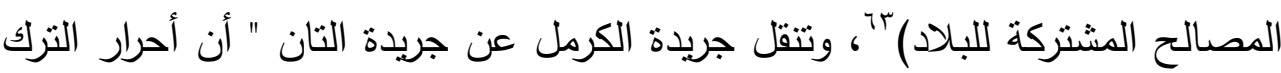
يعاونون اليهود على تكوين قومية يهودية في فلسطين، لأن ذلك يحول دون أماني العرب بالاستقلا، فإذا كان بعض الموظفين يسهون بيع الأراضي للصهيونيين

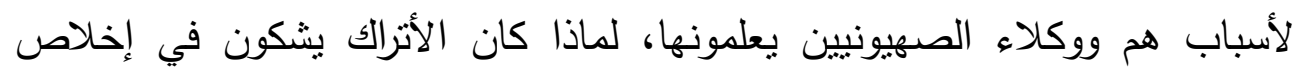
العرب فما هذه طريقة لاستجلابهم" •. ومن التغيرات التي جرت في فلسطين في فترة حكم الاتحاديين زيادة مساحة الأراضي التي سيطر عليها اليهود في فلسطين، وذلك من خلال المزادات التي كانت الحكومة تقيهما بسبب حاجتها إلى المال خاصة على أراضي السلطان عبد الحميد " الجفاللك " حيث أقيمت عدد من المزادات، في محاولة لطرد الفلاحين من أراضيهم الأمر الذي أثارهم ضد الحكومة والمهاجرين. وبدلاً من الإصلاح الذي رفع شعاراً لهم، أخذ الاتحاديون في زيادة الضرائب على الأهالي وخاصة الفلاح فقد تم إضافة 7\% على ضريبة الوبركو باسم تجهيزات عسكرية، وذلك مع إعلان الاستور العثماني، وبعد حرب البلقان r r 19 تم إضافة \% ع على الأراضي لأجل تغطية العجز الذي طرأ على الموازنة، ثم أضيف إليها 0\% باسم الأسطول، وبموجب قانون المؤرخ في ع ا حزيزان عام • (9 ا تم تبديل 


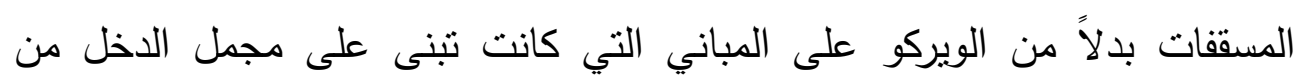
الأملاك المبنية 10.

وتصف الوثائق البريطانية ما حصل في عهد الاتحاديين للفلسطينيين سكان

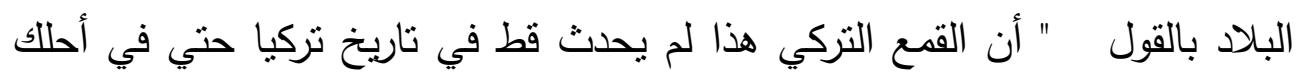

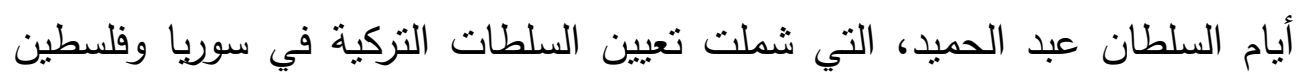

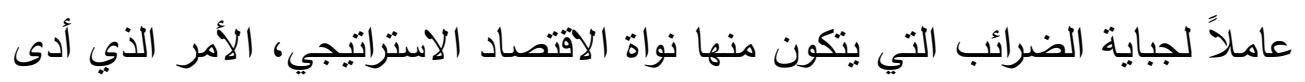

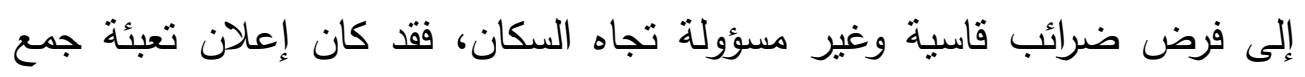

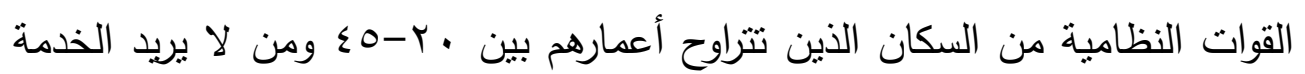

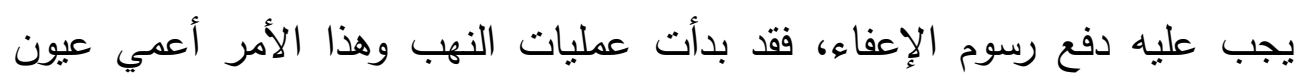

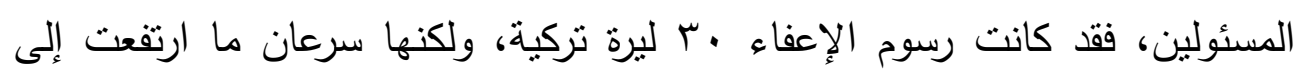

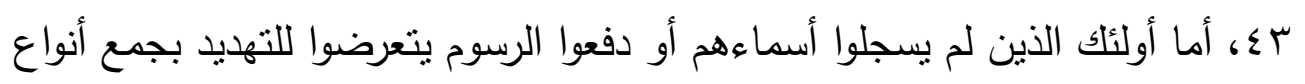

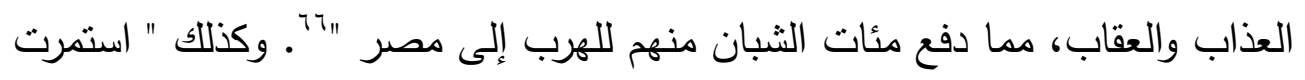

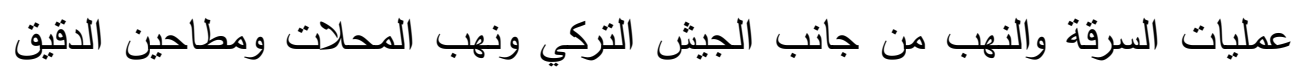

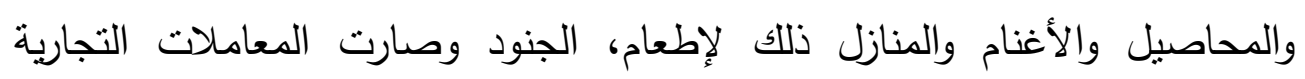

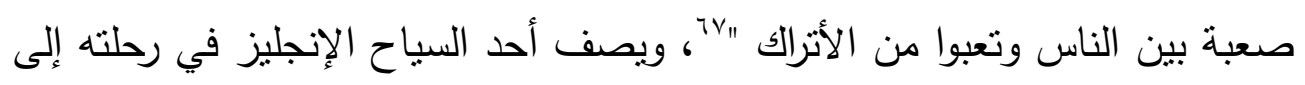

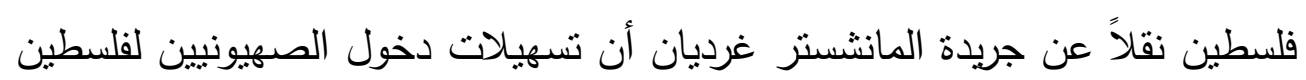
بعد الدستور تسرع بشكل ملفت للانتباه حيث قربت الاعتراف بان باللغة العبرانية كلغة

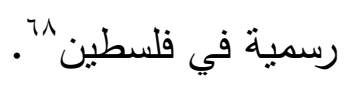

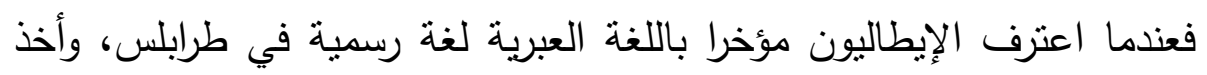

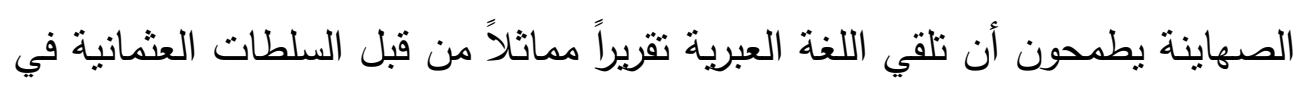

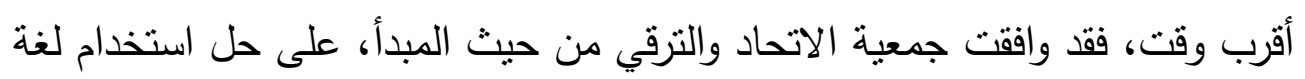

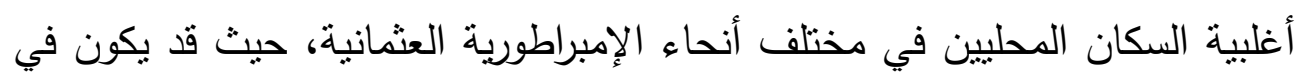

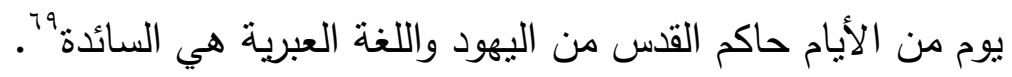


وبعد مواجهة الحكومة للفلاحين وأهل فلسطين، أدركت الحكومة ضرورة العمل على تهدئة الفلاحين حيث تذكر الوثثقة " أن الحكومة قررت صرف النظر عن إقامة المزادات على الأملاك والأراضي المدورة الواقعة في فلسطين والمجاورة لها إلى لى له اليهود، حيث إنها لم تقدر على منعهم من الاشتراك في المزادات، وذلك لأنهم أصبحوا من الرعاة العثمانيين "•، وجاء منع التفاوض مع اليهود بخصوص الأراضي في

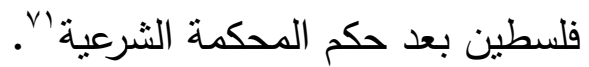
وقد أصاب فلسطين خلال فترة حكم الاتحاديين هجرة أعداد كبيرة من أهالي

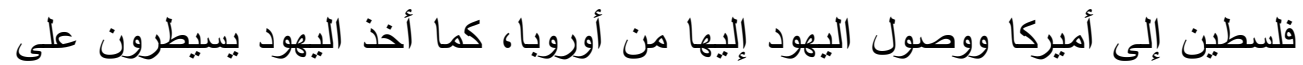
الاقتصاد الفلسطيني، وترى جريدة فلسطين " أن الأدمغة التي تشتخل هذا الشغل في فلسطين هي أدمغة أوروبية "Yr"، والجدير بالذكر أن الحكومة من ناحية الشكل كانت تعارض الاستيطان، لكن ليس بالقدر الكافي فقد كانت تشرع في التسهيلات للصهيونيين، ولكنها كانت حذرة في هذا، فلم يكن خافياً أمر المعارضة العربية للاسنيطان اليهودي في فلسطين، ولكن هذا لم يمنع الحكومة من إصدار القوانين التي ساعدت اليهود في عملية الاستيطان من خلا عمل الحكومة على سد طريق القومية العربية.

ومع هذا ظل نفوذ رجال الحركة الصهيونية في الدولة واضحاً لاستعمار فلسطين وإعادة ملك بني إسرائيل إلى - وطنهم الأول- وإلى ابتلاع أصحاب الملابين من خيرات البلاد "، فقد ساعدت الحكومة العثمانية الحركة الصهيونية بإسكات كل معارضة لها، وخاصة في فلسطين حتى يتم العمل في سرية تامة دون إثارة أهل البلاد، والصحف اليومية التي كانت رأس الحربة في وجه التقدم الصهيوني في الاستيلاء على الأراضي وكثف كل صغيرة وكبيرة من أعمالهم. وقد أصاب أهل فلسطين بشكل عام - بعد أن طردوا من بيوتهم نتيجة شراء اليهود الأراضي الفلسطينية - هجرة قسم كبير منهم إلى البداوة (الفلاح الفلسطيني) الذي كان بعتمد على الزراعة كوسيلة للعيش عَ، ونتيجة لذلك تشكلت طبقة برجوازية 
لا تهتم بالفلاح بل بالطبقات العليا، على الرغم من أن المجتمع العثماني يتصدر فيه

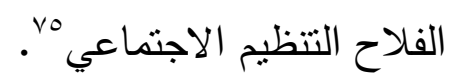

وكان أثد هذه التغيرات - لا من ناحية الثكل إنما من ناحية المضمون على الثى

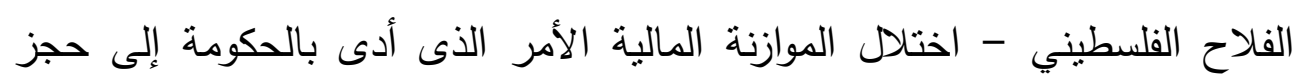
نصف رواتب الموظفين واستفحل الظلا في جباية الأموال الأميرية وطرح الأعثار وتنابق الموظفون إلى زيادة أعشار في الأقضية والألوية، وزد على ذلك الديون العمومية والإعانات المختلفة، ولقد اقتسم الفلاح القسم الأكبر منها، ويصف الثيخ محمد رشيد رضا الأمر بقوله " لقد سمعت كثيراً من الفلاحين أنهم اضطروا إلى بيع أراضيهم وتزويج بناتهم ليأخذوا صداقهن ويعطوا للجباة ما يطالبونهم به من الأموال

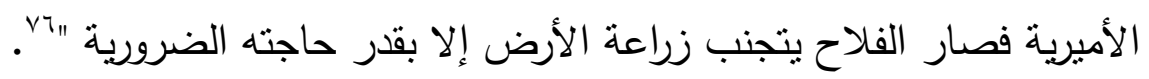

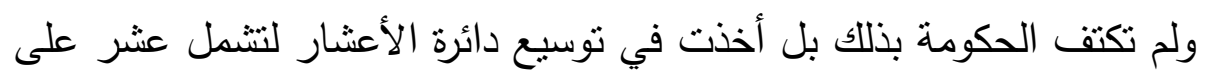
بساتين البرتقال، ووضع مبلغ مالي على كل قطعة أرض ولم وأصبحت عمليات الاحتيال والفساد من الحكومة التركية وجامعي مخالفات الضرائب في القس المشهورين سيئ السمعة، فالعشر القانوني عشر من منتجات الأراضي الصالحة للزراعة، ولكن كيف تم احتجاز خمسة أو ستة أعشار بدلاً من عشر واحد، وكان

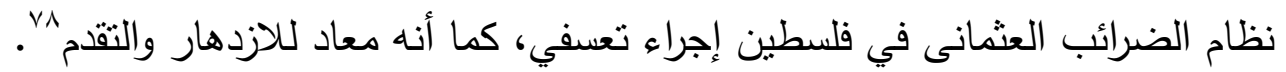
وكان من أهم المتغيرات التي أصابت فلسطين في عهد حكم الاتحاديين فساد الإدارة، هذا ما تؤكده جريدة الكرمل لمتصرف القس الذي كان يرى المستعمرات

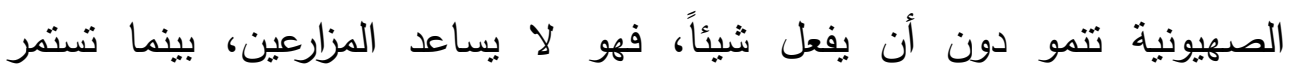
المستعدرات في النمو، بسبب تقصير الموظفين الذين يرون مع متصرف القدس بعدم

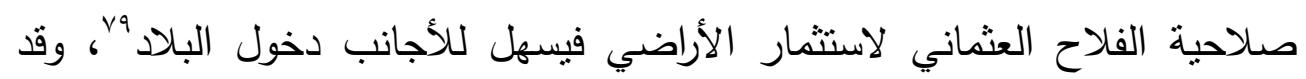

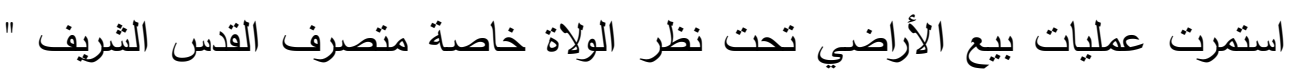
عزمي بك " فقي رسالة من الكاتب ميشال يدوتي من يافا يطالب المتصرف بمنع عمليات بيع الأراضي خاصة أراضي المشاع التي تتنقل من شخص إلى شخص كل 
عام لأنهم لا يستعيطون الاستفادة منها، لهذا على متصرف القس توزيع هذه الأراضي على الفلاحين، وعدم بيعها إلى اليهود حيث ثم بيع قرية " دجن " لأن هئ لهاه الفلاحين يعانون من الفقر الثديد •^. فقد ازدادت أعداد العنصر اليهودي خلا السنوات العشر الأخيرة - إي منذ 7.9 19- فتم شراء الأراضي، وبدلاً من التعاون بين اليهود الذين يأتون من روسيا

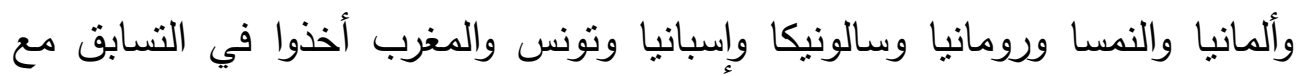
الصهيونيين معتمدين على إخوانهم الأغنياء في أوروبا'ئ. فقد كان ضعف ولنف الإدارة العثمانية هو السبب الرئيسي لتقدم الحركة الصهيونية في العملية الاستيطانية في فلسطين دون أبي قرارات تحمل صفة الجدية تدعو فيها للخطر الصهيوني، والجدير بالذكر أن الحكومة العثمانية لم تصدر قوانين صارمة ضد الحركة الصهيونية، وإن أصدرت قوانين لم تكن ملزمة لليهود مع تردي أوضاع الدولة العثمانية التي كانت تحارب على أكثر من جهة.

وعلى الرغم من حسن المعاملة التي ثلقاها اليهود الدولة في العثمانية زمن الاتحاديين، إلا أن الأمر لم يعجب اليهود، ففي مذكرة مرسلة إلى العاصمة واشنطن

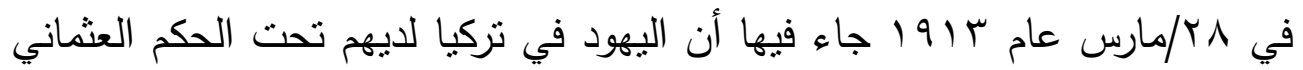
الحرية لممارسة حقوقهم المدنية في أمن وكذلك حقوقهم الدينية، كما كان للحاخام الأكبر مساواة مع الطوائف الدينية الأخرى به. وبعد خطاب الحاخام اليهودي في استانبول بعد الانقلاب طلب مباشرة من وزير العدل والثقافة إزالة القيود عن الهجرة وحيازة الأراضي بدعوى أن هذه الإجراءات تجرح وبعدق الحس اليهودي الوطني، مع وجود معارضة من ضباط الحكومة والرأي العام على إتمام إلغاء دخول اليهود الأجانب للقس، وشراء الأملاك على أثز زيارة حاخام اليهود حاييم ناحوم، ولكن هذاء

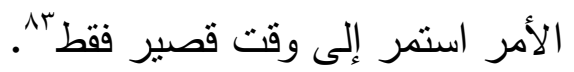
وقد تغير موقف الاتحاديين من اليهود والحركة الصهيونية - الثريك الحقيقي للاتحاديين في الانقلاب على السلطان عبد الحميد - بعد اكتشاف تجسس اليهود في 
فلسطين لصالح بريطانيا عدوة الدولة العثمانية الأولى، وتترح إحدى الوثائق العثمانية

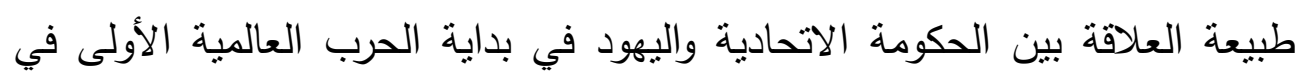

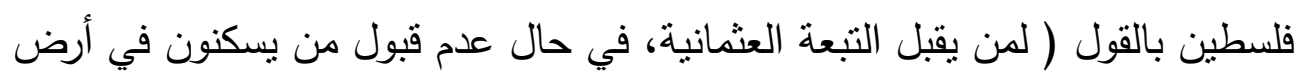

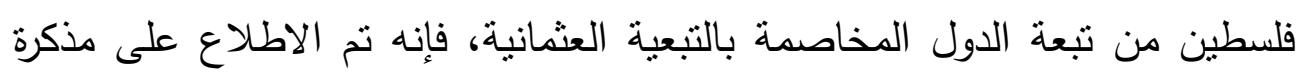

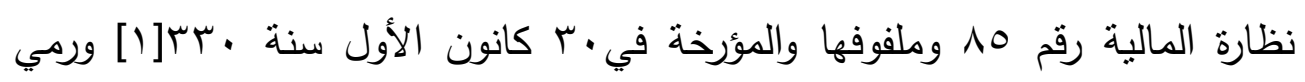

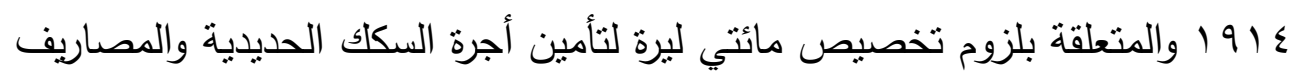

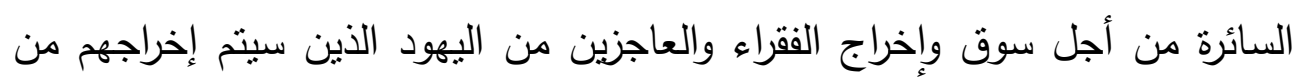

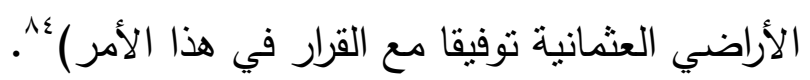

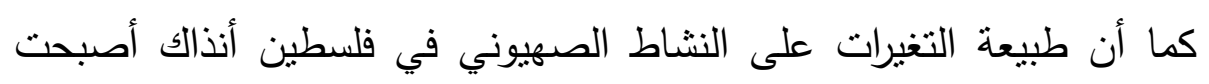

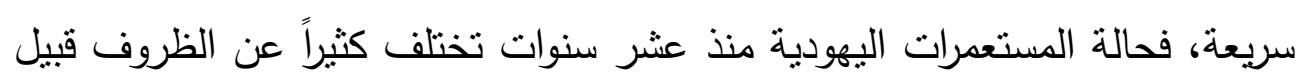

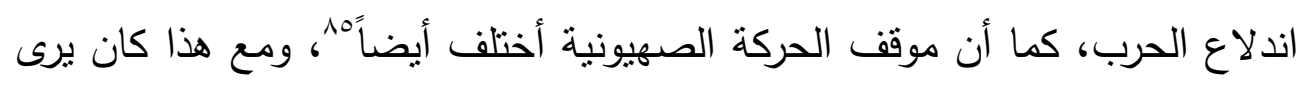

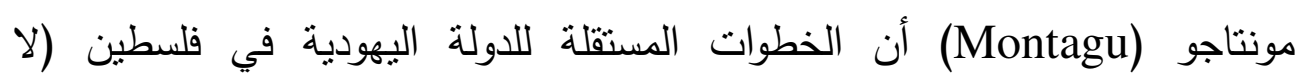

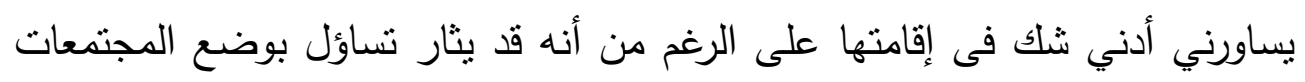

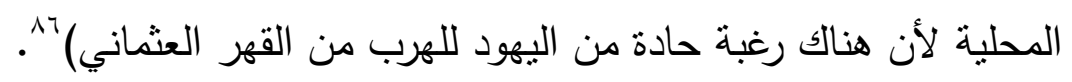

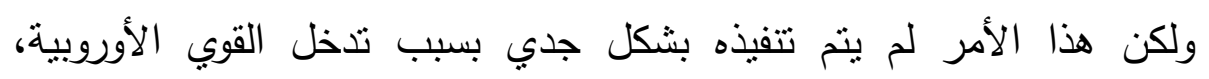

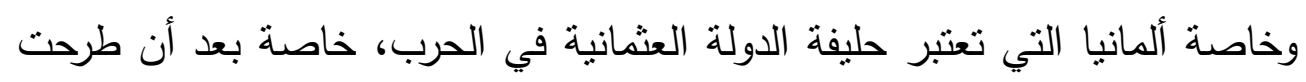

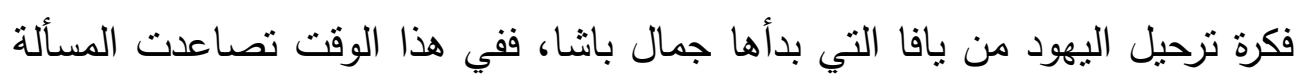

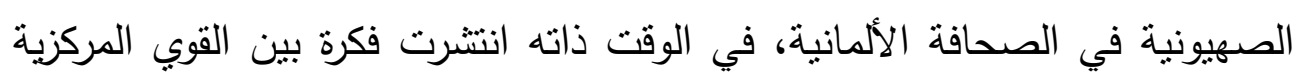

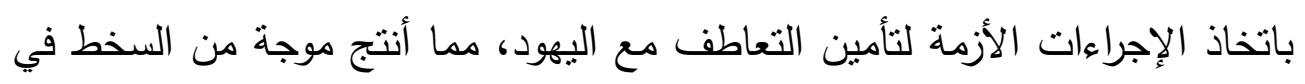

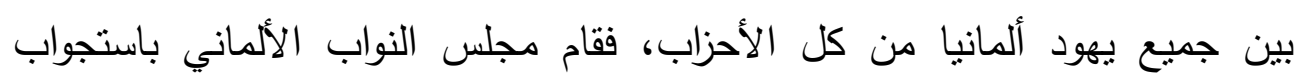

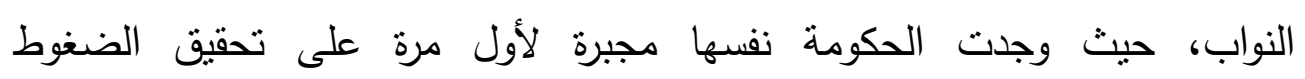

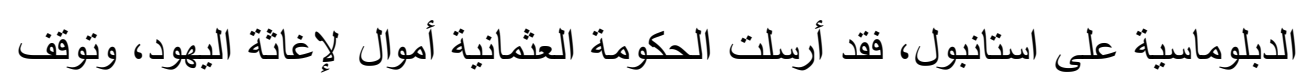

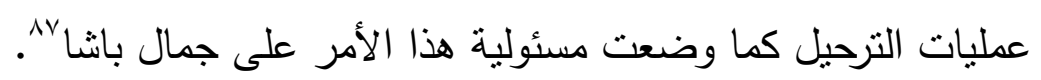

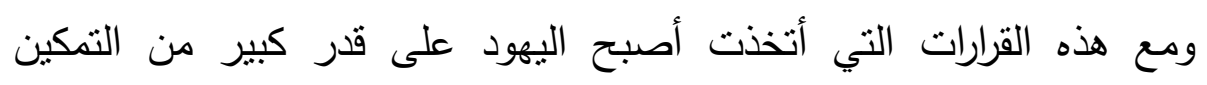


فأصبحوا تحت الرعاية العثمانية، بعد أن أصدرت جمعية الاتحاد والترقي قراراً بالمساواة بين جميع سكان الدولة العثمانية وهو ما كان بنطبق على اليهود، أما اليهود الذين لم يكونوا تحت رعاية الدولة العثمانية، فقد كانوا تحت رعاية الدول الأجنبية يحملون جوازات السفر تللك البلاد، وكذللك ساعد موظفو الدولة اليهود على الفرار من كل القيود بمجرد حضور المال، وأدت التغيرات التي طرأت على فلسطين أثناء فترة حكم الاتحاديين إلى زيادة قوتهم و أعداهم ومستعمراتهم. وعلى الرغم من إجراءات الحكومة التركية منذ عام 1910 ضد اليهود المستعمرين في فلسطين من مصادرة ممتلكاتهم مما تسبب في حالة من عدم الرضا بين يهود ألمانيا، مع أن هذه الإجراءات وعمليات التزحيل كان مبالغاً فيها إلى حد بعيد، فقد نوقشت القضية الفلسطينية بعد ذلك خلال مقابلة جمال باشا مع الفون

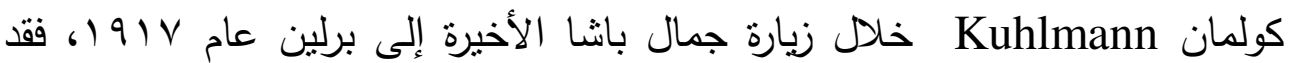
كانت ألمانيا تخشي استغلال إنجلترا للعنصر اليهودي، ومحاولة حصول إنجلترا على حماية اليهود والدعم الصهيوني نظراً للأهمية الصهيونية بالنسبة للمشروع البريطاني، فقد قامت الحكومة البريطانية بالترحيب بقرارات الحكومة الألمانية، وفي الوقت نفسه أثثي وزير الخارجية العثاني على اليهود اللاجئين وعلى ولائهم وصناعتهم ^، وقد

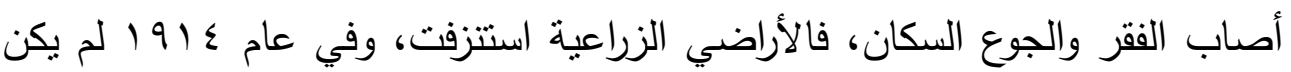
الفلسطينيون يعانون كثيراً، ولكن مع السنة الثانية من الحرب بدأ المسلمون في فلسطين يعانون، حيث وصل سعر كيلو القمح إلى 0؛ فرنكاً، ثم بدأ الناس يأكلون الثعير والأعثاب البرية، كما انتشرت الأمراض بينهم خاصة وباء التيفوس، أما الجاليات اليهودية في فلسطين فقد تلقت الدعم بسرعة وخاصة من لجنة الإغاثة الأمريكية وكانت الإجراءات التي اتخذتها الحكومة البريطانية في نهاية حكم الاتحاديين عام •.9 ابعد مطالبة اليهود بذلك بمثابة إعلان الأحكام العرفية لحيازة جميع الأراضي غير المزروعة، وبضغط من اللجنة الصهيونية استطاعت الحصول على 
الأراضي المجاورة للمسجد الأقصى، مما خلق حالة استياء بين المسلمين في البلاد

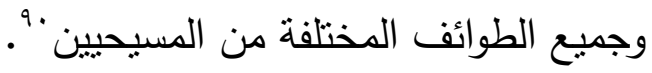
وكانت سياسة بربطانيا في فلسطين تعمل على تمكين اليهود إلى أبعد الحدود، وذلك من خلال قلب القوانين الدستورية والمحلية وتجاهل حقوق العرب، وخلال إحدى جلسات المناقثنة صريح أحدى النواب، وبلا شك أننا نقوم بذلك نيابة عن اليهود وليس نيابة عن المصالح البريطانية، لذلك طالبث الحركة الصهيونية بضم كل الأرضي الجيدة المزروعة أو الأراضي التي يمكن زراعتها دون مخطط للري بهدف تحقيق

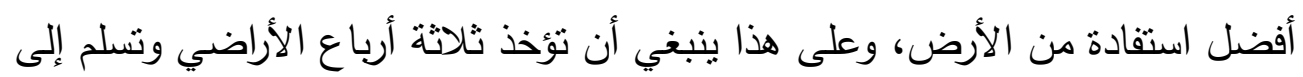

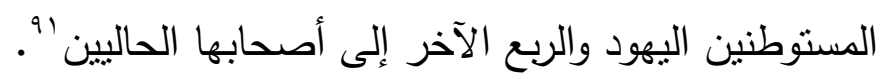
وقد قامت بريطانيا في الثهور الأولى للحرب بتقديم الدعم لليهود من خله المحادثات في الوزارة البريطانية لخلق دولة يهودية في فلسطين، حيث قام ديفيد لويد جورج مستشار وزير الخزانة إلى السير إدوارد جراي وزير الخارجية، بالعمل على

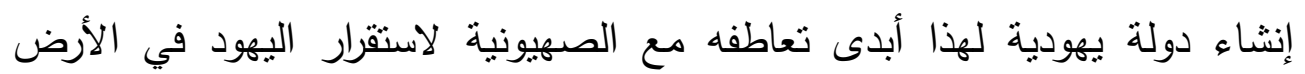
المقدسة 


\section{الههوامش}

${ }^{1}$ Simon, Leon: Zionism and the Jewish problem, published by the Zionist organization, London bureau, piccadilly, London, 1918, p 14.

${ }^{2}$ Stein, Leonard: Zionism, Ernest Benn ltd, London, 1925, p 97.

${ }^{3}$ F.O 424/222 No. 2, From Mr. Marling to Sir Edward Grey, Constantinople, December 27, 1909.

${ }^{4}$ Ibid.

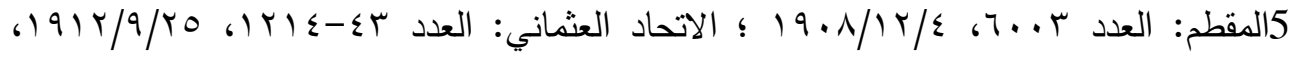

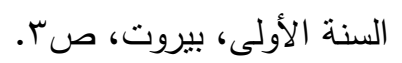

6ذكرات محمد عزة دروزة: سجل حافل بمسرة الحركة العربية والقضية الفلسطينية خلال قرن من سن

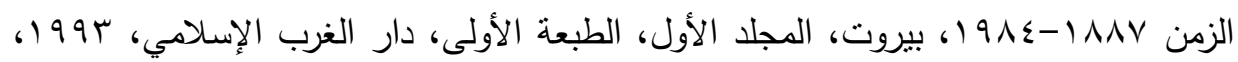

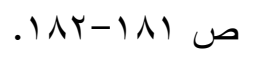

7نعمان عاطف عمرو: مظاهر الوعي بالقومية العربية في فلسطين حتي عام • ب9 ا، فلسطين،

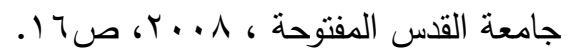

8 عبد الوهاب الكيالي: تاريخ فلسطين الحديث، بيروت، المؤسسة العربية للاراسات والنشر، الطبعة

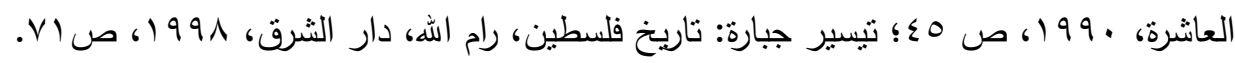
9محمد عزة دروزة: المصدر السابق، ص ع1) ا. 10 محمد كرد علي: خطط الثام، الجزء الثالث، دمشق، الطبعة الثالثة، مكتبة النوري للنشر، بره 19،

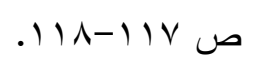

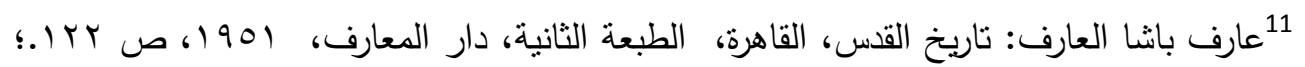

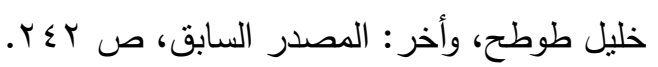
12 المنار: الأمة العثمانية والدستور، المجلد الحادي عشر، الجزء السابع، 19 19، ص بــ. 


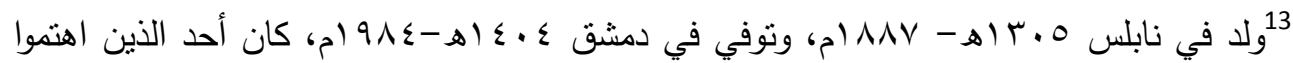

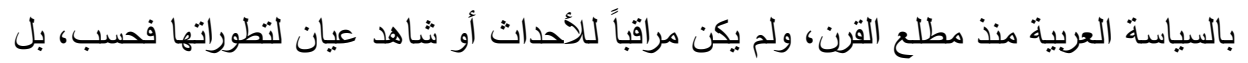

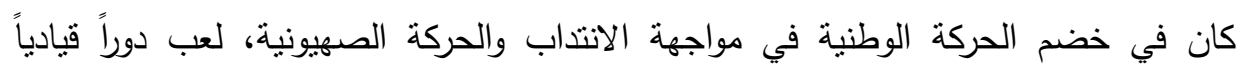

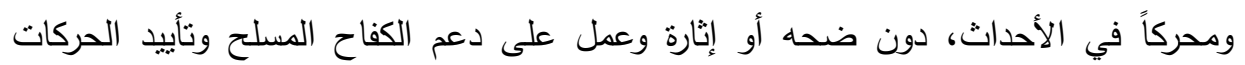

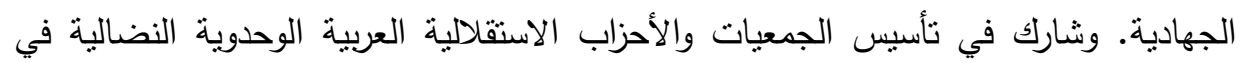

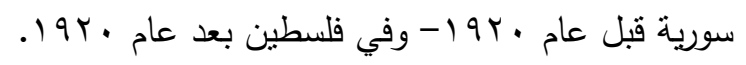
14 محمد عزة دروزة: مصدر سابق، ص عه ا.

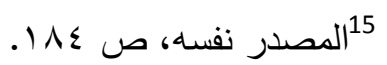
16

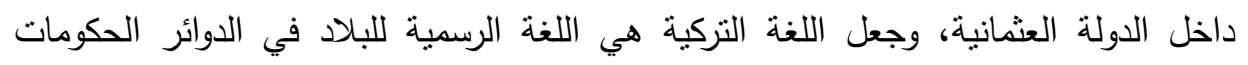

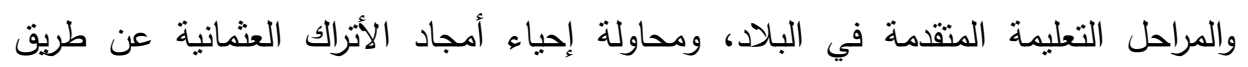
السياسة الطورانية.

17 Ahmad, Feroz: Development of secularism in turkey, C. Hurst Co. Publishers 1td, London. 1998, p 332.

18 ولد موئير كوهين في سالونيك عام به ام، وتخرج من مدرسة الحقوق ، أخذ يكتب في جريدة "

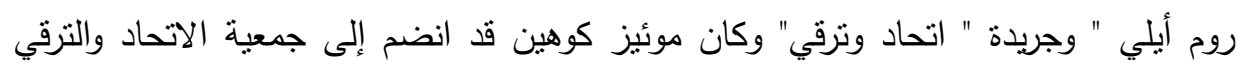

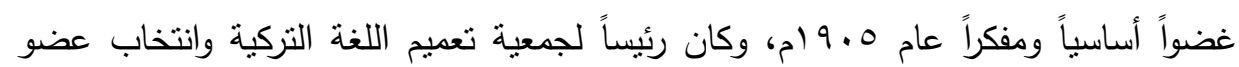

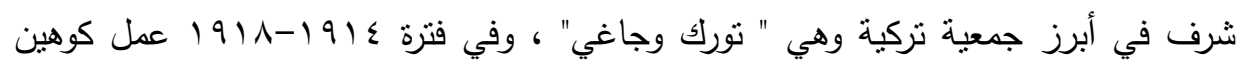

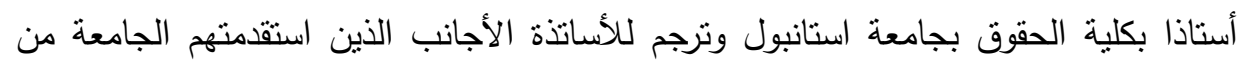

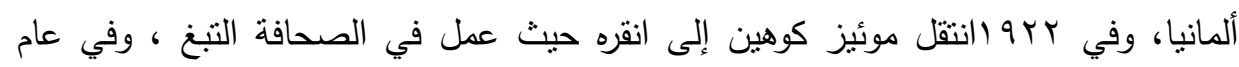

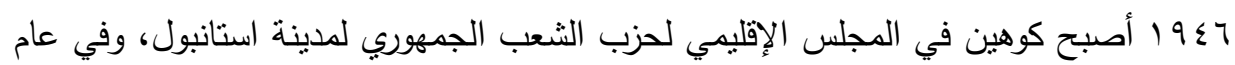
• 90 ام شح هذا الحزب موئيز كوهين عضواً بجلس الأمة عن استانبول ، وحتى لا ثير القراء

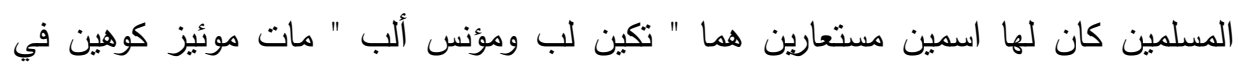

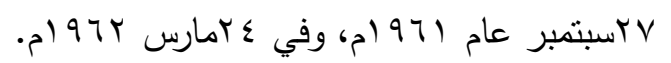

19 حمد حرب: مذكرات السلطان عبد الحميد، دمثق، الطبعة الثالثة، دار القلم، (991، ص م9. 


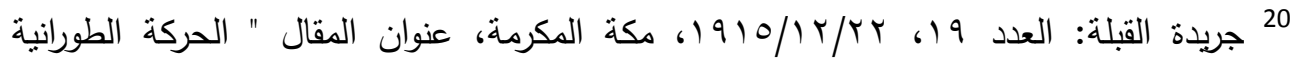
الجديدة في بلاد تركيا " صس لصناحب الجريدة محب الدين الخطيب.

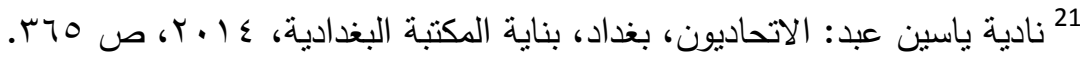

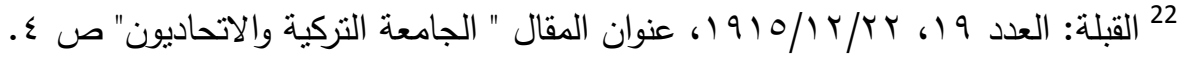
23 خيرية قاسمية: مواقف عربية من التفاهم مع الصهيونية ب ا9 19-ـ ا9 (19، مجلة شؤون فلسطينية،

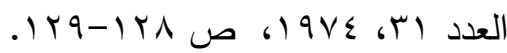

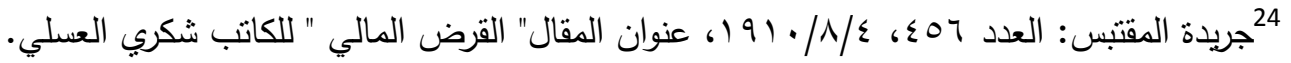

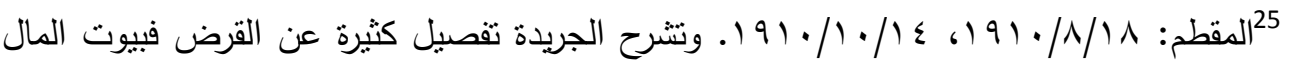
اليهودية ( كريدي موبيليه وبرنارد ودريفوس وجاريسلوسكي )

26/المنار: الانقلاب الخطر وجمعية الأحمرين الدم والذهب، المجلد الساد عشر، الجزء الثاني، .101

27 سمير أيوب: وثائق أساسية في الصراع العربي الصهيوني، وثيقة رقم ب1،، الجزء الأول، بيروت،

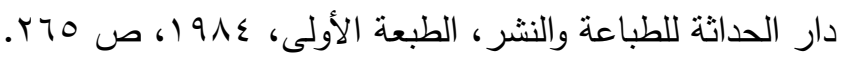

28 الهنار: اليهود في المملكة العثمانية، المجلد الرابع عثر، والجزء الثاني، 1919 1، ص 109. 29 Ahmad, Feroz: OP. Cit, p 334.

${ }^{30}$ F.O 424/222, OP. Cit.

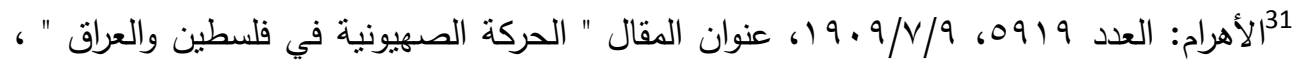
الكاتب جاك هرنشتين.

$$
\text { 232 }
$$

${ }^{33}$ Ahmad, Feroz: OP. Cit, p 335.

${ }^{34}$ F.O 424/222, OP. Cit.

35 المنار: اليهود في المملكة العثمانية، ص 109.

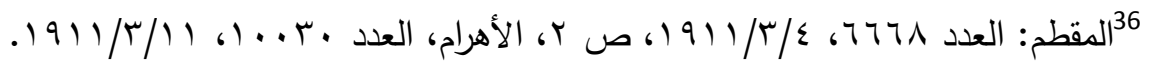




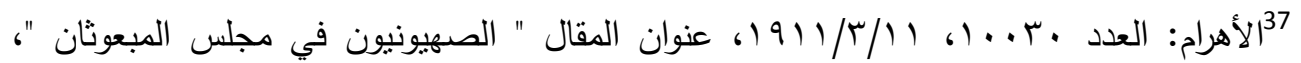
توقيع أ. هـ

38 F.O 424/240 No. 255, From Sir R. Rodd to Sir Edward Grey, Rome, December 13, 1913.

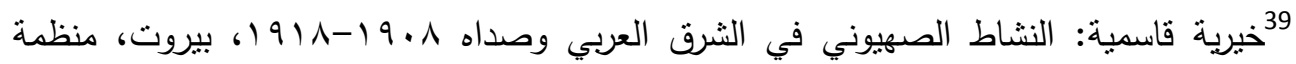

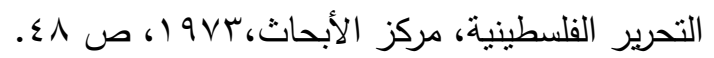

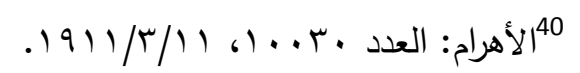

${ }^{41}$ F. O. 882/14, Memorandum of the Jewish Palestinian Question, 5/2/1917. ${ }^{42}$ Stein, Leonard: OP. Cit, p 59.

43 Jannaway G, Frank: Palestine and the powers or the intentions and aims of Russia Germany Britain and turkey regarding the Zionist movement in the light of prophecy, London, Elliot stock, 1918, p76.

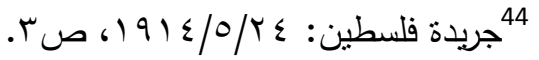

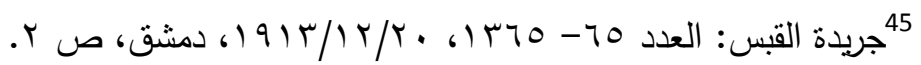

$$
\begin{aligned}
& \text { 46خيرية قاسمية: مواقف عربية من التفاهم مع الصهيونية، ص وب ا. }
\end{aligned}
$$

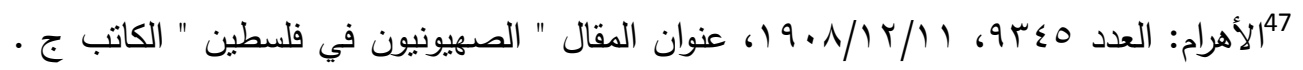
هرنشتنين.

48 F.O 424/238, No. 12 Form Sir G. Lowther to Sir Edward Grey, Constantinople, March 17, 1913.

49 ناجي علوش: مختارات المفيد عبد الغني العريسي، بيروت، دار الطليعة، دون ناريخ، ص سץ.

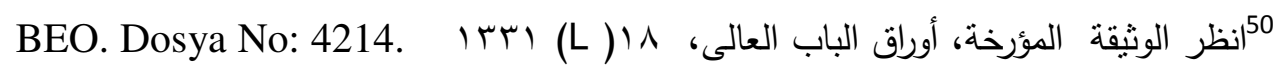

Gomlek No: 316042

51 F.O 424/240 No. 279, Form Sir Louis Mallet to Edward Grey, Constantinople, December 21, 1913.

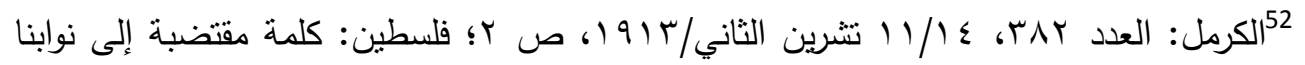

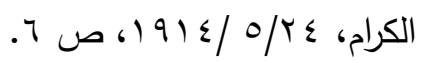




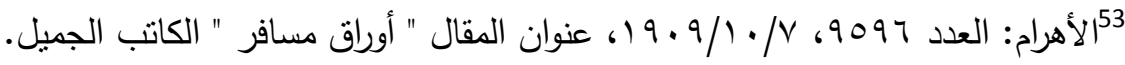

54 The Jewish herald, ( Houston Texas ) November 11, 1909, p3.

55 F.O 424/229, No. 829, From, Sir G. Lowther to Sir Edward Grey, November 18, 1911.

56 خيرية قاسمية: النشاط الصهيوني في الثرق العربي وصداه، ص $7-77$.

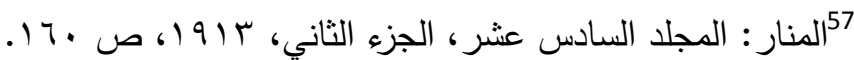

58 5عسى صوفان القدومي: فلسطين وأكذوبة بيع الأرض، فلسطين، مركز بيت المقد للاراسات

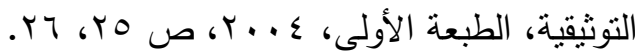

59 هند أمين البديري: أراضي فلسطين بين مزاعم الصهيونية وحقائق التاريخ، القاهرة، الأمانة العامة،

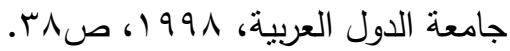

60 مجلة الحقوق: مشروع قانون نزع ملكية الأراضي، فلسطين، الجزء الثالث ، السنه الأولى،

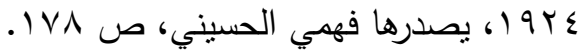

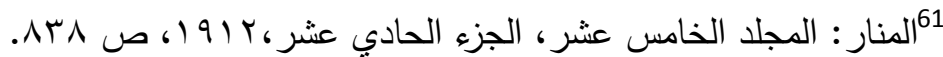

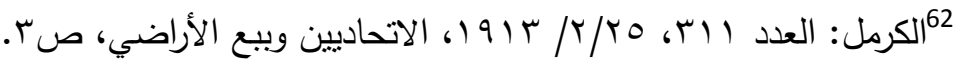
33 المقط:

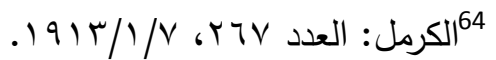

65 عارف العارف: الدفصل في تاريخ القس، الجزء الأول، القس، مطبعة المعارف، الطبعة

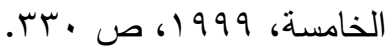

${ }^{66}$ F.O $882 / 14$, the state of affairs in Palestine by native of Jerusalem $17^{\text {th }}$ September 1914, From, Anis ELGamal, $20^{\text {th }}$ September 1914.

${ }^{67}$ Ibid.

$$
\text { 68 فلسطين: العدد 0. . }
$$

${ }^{69}$ F.O 424/240, No. 279, OP. Cit. 
BEO. Dosya No: 3781, Gomlek No: انظر إلى الوثيقة المؤرخة، أوراق الباب العالى، 283552, 12/B/1328

BEO. Dosya No: 3782 Gomlek No: النظر إلى الوثيقة المؤرخة، أوراق الباب العالى 283630, 14/B/1328

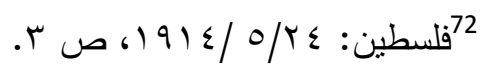

737المنار : المجلد الرابع عشر، الجزء الرابع، 19 (1، ص 979.

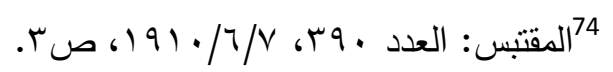

${ }^{75}$ Ahmad, Feroz: OP. Cit, p 329.

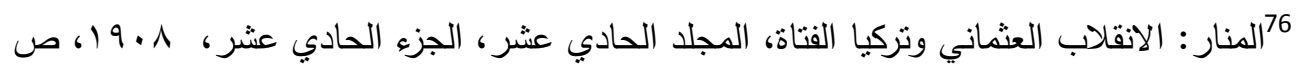
. $\wedge \leqslant \varepsilon-\lambda \leqslant \mu$

$$
\text { 77/المقط: العدد1077، 1/ / / / 191، الكاتب ميشال يدوتي ، وطني حر، صع. }
$$

${ }^{78}$ F.O. 882/14, The Politics of Jerusalem, this summary is the result of enquiries made this week of several of Jerusalem now in Cairo, and who left break of war with Turkey in the autumn of 1914, From captain Arab bureau, $29^{\text {th }}$ December, 1916.

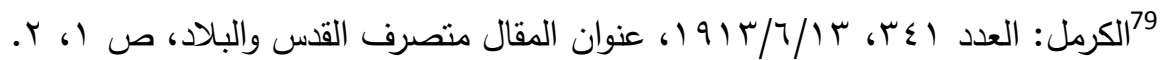

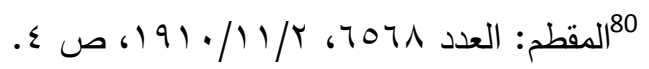

${ }^{81}$ F.O. $882 / 14$, OP. Cit, $29^{\text {th }}$ December, 1916,

82 The American Jewish committee meeting of executive committee held on January 1, 1913, Philadelphia.

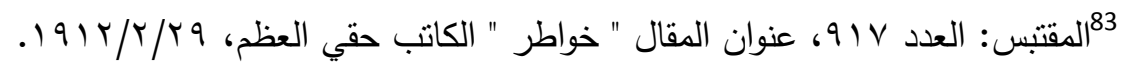

848نظر الوثثقة، مجلس الوكلاء، ورقة مخصوصة بمناقثات، عنوانها " عند إخراج اليهود الذين لا

يقلون التبعة العثمانية من فلسطين تتحمل الحكومة العثمانية نفقات سفر المعدمين من بينهم" "

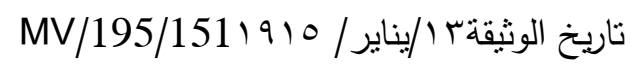

${ }^{85} \mathrm{CAB} / 24 / 10$, G. T. 447, Zionism and the suggested Jewish rattalions for Egyptian expeditionary force, $14^{\text {th }}$ April. 1917, sgd. W. Ormsby Gore. . 
${ }^{86}$ CAB/24/28, G. T. 2263, Zionism, $9^{\text {th }}$ October 1917, E. S. Montagu.

$87 \mathrm{CAB} / 24 / 42$, G. T. 3635 , memorandum on the attitude of enemy Governments towards Zionism, Intelligence Bureau, Department of Information Section, 1918.

${ }^{88}$ Ibid.

${ }^{89}$ F. O. 882/14, on present economic and political conditions in Palestine, 28 Jan. 1917.

${ }^{90}$ Parliamentary Debates House of Lords, Official Report, Fifth Series, June 29, 1920,vol. 40, col. 1005, " Henceforth cited as parl. Deb. HL

${ }^{91}$ Ibid.

${ }^{92}$ Muller, w. James: Churchill as peacemaker, Cambridge University press, United Kingdom, 1997, p 218. 